\title{
Depression of streptomycin production by Streptomyces griseus at elevated growth temperature: studies using gene fusions
}

\author{
V. Jayne Deeble, ${ }^{1}$ Helen K. Lindley, ${ }^{1}$ Mohammiad Reza Fazeli, ${ }^{2}$ \\ Jonathan $\mathrm{H}$. Cove ${ }^{2}$ and Simon Baumberg ${ }^{1}$
}

Departments of Genetics 1 and Microbiology2, University of Leeds, Leeds LS2 9JT, UK

\author{
Author for correspondence: Simon Baumberg. Tel: +44 113233 3080. Fax: +44 1132441175. \\ e-mail: GEN6SB@SOUTH-01.NOVELL.LEEDS.AC.UK
}

\begin{abstract}
Streptomyces griseus ATCC 12475 fails to produce streptomycin when grown at $34{ }^{\circ} \mathrm{C}$ or above, although growth is appreciable up to at least $37{ }^{\circ} \mathrm{C}$. This depression of streptomycin production at elevated growth temperature is manifest equally in liquid and on solid, and with complex and minimal, media. We report studies with gene fusions of the reporter genes aph or $x y l E$ to restriction fragments containing the streptomycin biosynthesis promoter PstrB1. aph constructs were in high, and $x y / E$ constructs in low, copy number vectors. Two strB1 promoter fragments were used, one requiring activation by the pathway-specific activator StrR of S. griseus, the other reportedly activator independent. PstrB1 expression in the aph constructs in S. griseus and in $S$. lividans was significantly reduced at $37^{\circ} \mathrm{C}$ compared to $30{ }^{\circ} \mathrm{C}$. Some of this reduction could be explained by lower plasmid copy number at the higher temperature, but strR-dependent expression was clearly temperature controlled. Using the xylE reporter system, the temperature dependence of PstrB1 expression was confirmed but, surprisingly, the strR dependence of the two promoter fragments differed from that observed in the multicopy aph constructs. These data identify a temperature-dependent promoter which may contribute to the depressive effect of elevated growth temperature on streptomycin production.
\end{abstract}

Keywords: antibiotic production, antibiotics, regulation of secondary metabolism, Streptomyces, streptomycin

\section{INTRODUCTION}

Secondary metabolite production in streptomycetes is subject to complex physiological and environmental controls (Martín \& Demain, 1980). A frequent finding is that growth at elevated temperature leads to a marked depression in production or none at all (Votruba $\&$ Vanek, 1989). Three hypotheses accounting for this effect postulate at the elevated growth temperature: (i) lowered expression - which may involve reduction in transcription, translation initiation, or mRNA stability, or any combination of these - of one or more genes whose products are needed for secondary metabolite synthesis; (ii) in vivo heat lability of one or more proteins involved in secondary metabolite production; and/or (iii) diminished

Abbreviations: APH, aminoglycoside 3'-phosphotransferase; $C O$, catechol oxygenase. availability of precursors due, in some way, to the altered physiological state of the culture. In principle, hypothesis (i) can be distinguished from (ii)/(iii) by its testable prediction of diminished gene expression at the elevated temperature.

One of the best-characterized secondary metabolite systems in terms of regulation is streptomycin biosynthesis and resistance in Streptomyces griseus (Retzlaff et al., 1993; Piepersberg, 1994). str genes, encoding enzymes of streptomycin synthesis, are activated by the presumably pathway-wide activator StrR (Distler et al., 1987b, 1992). Current models suggest that physiological and environmental parameters determine, through a regulatory cascade, the expression of strR and thus the internal level of StrR, which in turn controls the extent of activation of the biosynthetic genes (Vujaklija et al., 1993; Piepersberg, 1994). We have studied regulation at the promoter PstrB1, which directs expression of the strB1 gene; the gene order 
in this region of the $S$. griseus chromosome is $\operatorname{str} D$ $\operatorname{str} R-a p h D(=\operatorname{str} A)-P \operatorname{str} B 1-s t r B 1$, where $a p h D$ encodes the major streptomycin resistance enzyme, the 6-phosphotransferase (Retzlaff et al., 1993). We report here the use of fusions of PstrB1 to the reporter genes aph and $x y l E$ in distinguishing between the above hypotheses (i) and (ii)/(iii) as to the nature of the effect of elevated growth temperature on streptomycin production.

\section{METHODS}

Bacterial strains and plasmids. The bacterial strains used were S. griseus ATCC 12475 and S. lividans TK54 (Hopwood et al., 1983), a bis leu Spc derivative of 1326 . The plasmids used are listed in Table 1, and the structures of the gene fusions employed are shown in Fig. 1.

Media and growth conditions. Complex media R5 and YEME, and minimal media MM and NMMP, were as in Hopwood $e t a l$. (1985); modified YEME was as in Fazeli et al. (1995). Spore suspensions were prepared according to Hopwood et al. (1985).

The following growth regimes were used with liquid media. For the estimation of streptomycin production in liquid media, $S$. griseus spores were inoculated either directly into the final modified YEME or MM medium, or used to provide a vegetative preculture as follows. Spores were inoculated into modified YEME and grown at $30^{\circ} \mathrm{C}$ to provide a first preculture, which was inoculated either into the final modified YEME or into MM to provide a second preculture, the latter being inoculated into the final MM. The modified YEME or MM cultures were incubated at the appropriate temperature, the mycelium being sampled at intervals for estimation of dry weight and the supernatant medium assayed for streptomycin. (Further details are in Fazeli et al., 1995.) For the estimation of streptomycin yield at different temperatures, incubation was continued for up to $8 \mathrm{~d}$; the streptomycin level recorded was either the maximum or that attained at the end of incubation. For the growth of cultures to be assayed for APH (aminoglycoside 3"-phosphotransferase, encoded by aph from $\operatorname{Tn} 5$ ), inocula consisted of frozen aliquots of YEME precultures. These were inoculated into NMMP medium containing glucose and thiostrepton. Cultures were incubated at $30^{\circ} \mathrm{C}$ or $37^{\circ} \mathrm{C}$ for $72 \mathrm{~h}$ (S. lividans) or $48 \mathrm{~h}$ ( $S$. griseus); preliminary experiments showed that these time points gave the maximum enzyme activities, up to $30 \%$ above those of samples $24 \mathrm{~h}$ on either side. Mycelia were harvested, washed with phosphate buffer, resuspended in Tris $/ \mathrm{Mg}^{2+} / \mathrm{NH}_{4}^{+}$buffer, and disrupted ultrasonically, cell debris being removed by centrifugation to provide protein extracts. (Further details are in Lindley et al., 1995.) All liquid cultures in flasks were grown with coiled stainless steel springs.

The following growth regimes were used with solid media. For the estimation of streptomycin production on solid media, $10^{7}$ $S$. griseus spores were inoculated on to $9 \mathrm{~cm}$ diameter sterile dialysis membranes (Gallenkamp) on the surface of modified YEME or MM agar plates. The membranes were removed at appropriate times, the mycelium being collected for estimation of cell dry weight (carried out as for liquid cultures) and the underlying agar assayed for streptomycin (see below). For cultures to be assayed for $\mathrm{CO}$ (catechol oxygenase, the product of the $x y l E$ gene), spores were inoculated on to dialysis membranes on the surface of R5 plates supplemented with appropriate antibiotics. In this case, one membrane for each combination of plasmid pairing and temperature was removed daily; the mycelium was resuspended, disrupted ultrasonically, and freed of cell debris by centrifugation to provide protein extracts. (Further details are in Lindley et al., 1995.)

Estimation of streptomycin in culture media. For liquid cultures, this was performed by bioassay as in Vallins \&

\section{Table 1. Plasmids used in this work}

For pI J702, pI J486 and pI J2839, see Hopwood et al. (1985), Ward et al (1986), and Ingram et al. (1989), respectively. All the other plasmids are described in Lindley et al. (1995), and their construction is depicted in Fig. 1.

\begin{tabular}{|c|c|c|c|c|c|c|}
\hline Plasmid & & $\begin{array}{l}\text { Plasmid } \\
\text { vector/ } \\
\text { replicon in } \\
\text { Streptomyces }\end{array}$ & $\begin{array}{c}\text { Plasmid } \\
\text { vector/replicon } \\
\text { in } E \text {. coli }\end{array}$ & $\begin{array}{l}\text { Inserted } \\
\text { fragment } \\
\text { bearing } \\
\text { the PstrB1 } \\
\text { promoter }\end{array}$ & $\begin{array}{l}\text { Reporter } \\
\text { gene }\end{array}$ & $\begin{array}{c}\text { Inserted } \\
\text { fragment } \\
\text { bearing } \\
\text { an strR allele }\end{array}$ \\
\hline pHL623 & & pIJ486 & pBR322 & None & $a p b$ & None \\
\hline pHL708 & Fig. 1(b) & pIJ486 & pBR322 & 'Short' fragment & $a p b$ & None \\
\hline pHL614 & & pIJ486 & pBR322 & 'Long' fragment & $a p b$ & None \\
\hline pHL723 & & pIJ702 & None & None & $a p b$ & None \\
\hline pHL728 & Fig. 1(c) & pIJ702 & None & 'Short' fragment & $a p h$ & None \\
\hline pHL714 & & pIJ702 & None & 'Long' fragment & $a p h$ & None \\
\hline pIJ2839 & & SCP2* & pBR322 & None & $x y l E$ & None \\
\hline pHL308 & Fig. 1(d) & SCP2* & pBR322 & 'Short' fragment & $x y l E$ & None \\
\hline pHL314 & & $\mathrm{SCP} 2 *$ & pBR322 & 'Long' fragment & $x y l E$ & None \\
\hline pES2 & & pIJ702 & pACYC184 & None & None & None \\
\hline $\mathrm{pES} 2 s t r R$ & Fig.1(e) & pIJ702 & pACYC184 & None & None & strR \\
\hline $\mathrm{pES} 2 s \operatorname{sR} \Delta 7$ & & pIJ702 & pACYC184 & None & None & $\operatorname{str} \mathrm{R} \Delta 7$ \\
\hline
\end{tabular}


(a)

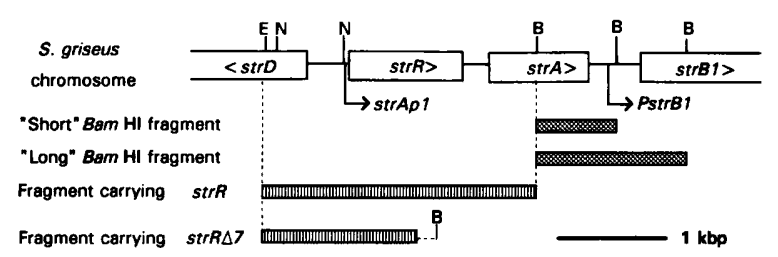

(b)

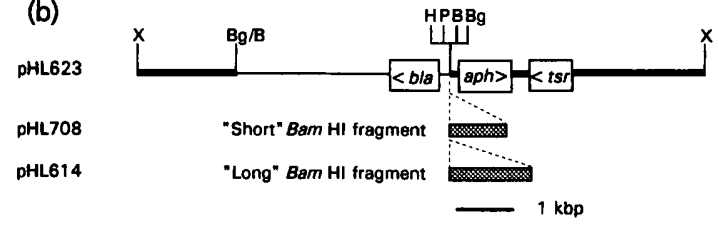

(c)

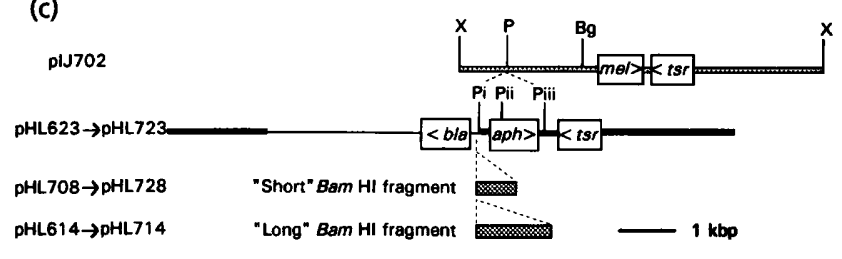

(d)

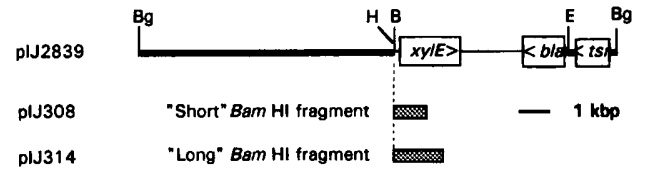

(e)

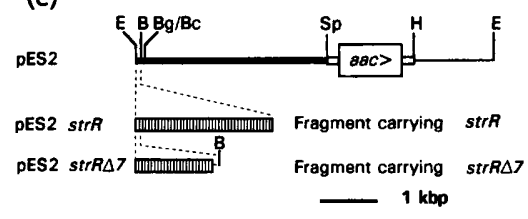

Fig. 1. Gene fusions used in this work. (a) Region of the $S$. griseus chromosome employed. Restriction sites: B, BamHI; $\mathrm{E}$, ECoRI; N, Nrul. Transcription startsites are denoted by arrows. The str $\Delta 7$ fragment is described in O'Neill (1992). (b) pHL623, 708 and 614. Restriction sites: B, BamHI; Bg, Bglll; H, Hindlll; X, Xhol. - and - represent DNA derived from plJ486 and pBR322 respectively (Lindley et al., 1995). (c) pHL723, 728 and 714. Restriction sites: Bg, Bg/ll; P, Pstl; X, Xhol. Pi, Pii and Piii are three of the Pstl sites within pHL623, 708 and 614 (the BamHI site in PHL623 into which the 'short' and 'long' fragments are cloned lies between $\mathrm{Pi}$ and the $5^{\prime}$ end of aph). (d) plJ2839, 308 and 314. Restriction sites: B, BamHI; Bg, Bg/lI; E, EcoRI; H, HindIII. - here represents DNA of Streptomyces origin (including the replication/maintenance region of SCP2*); - represents DNA of Gram-negative origin (including the $x y / E$ reporter gene and the replication region of pBR322). (e) pES2, pES2strR and pES2str $\Delta 7$. Restriction sites: B, BamHI; BC, Bcll; Bg, BgllI; E, EcoRI; H, HindIII; Sp, Sphl. - , - and $\square$ represent DNA derived from pIJ486, pACYC184 and pGM160, respectively.

Baumberg (1985) with the modifications of Fazeli et al. (1995). For cultures on solid media, $7 \mathrm{~mm}$ plugs of agar were removed from the medium underlying a mycelial mat on a dialysis membrane, and transferred to similarly sized wells in bioassay plates. The bioassay was carried out as in Fazeli et al. (1995).

Enzyme assays. APH, $\mathrm{CO}$ and protein were assayed as in Lindley et al. (1995). As described in that reference, $\mathrm{CO}$ activity was barely detectable in liquid-grown cultures, and for its estimation mycelia had to be grown by inoculation of spores on to a set of dialysis membranes placed on R5 agar appropriately supplemented with antibiotic(s), as indicated above. Activities shown in Table 3 were the maximum recorded with a particular set of membranes, usually in samples harvested at 3-4 d. Experiments (results not shown) showed that neither APH nor $\mathrm{CO}$ activities were reduced by holding protein extracts at $37^{\circ} \mathrm{C}$ for up to $2 \mathrm{~h}$, far longer than the length of any incubation employed in enzyme assays in this work. A further control was performed to check whether $\mathrm{CO}$ activity fell in vivo on incubation of mycelia at $37^{\circ} \mathrm{C}$. Cultures known to show high levels of $\mathrm{CO}$ (S. lividans carrying pHL308 and pHL314 together with pES2strR - see below) were incubated on solid media, in the usual way for $\mathrm{CO}$ assay, for $3 \mathrm{~d}$ at $30^{\circ} \mathrm{C}$ and then shifted to $37^{\circ} \mathrm{C}$. No consistent decrease in $\mathrm{CO}$ activities was found. Statistical tests on enzyme specific activities (standard deviation of means, $t$-test) were carried out according to Parker (1973).

\section{RESULTS}

\section{Streptomycin production by S. griseus at elevated growth temperature in liquid media}

S. griseus ATCC 12475 was grown in liquid complex or minimal media at temperatures from $20^{\circ} \mathrm{C}$ to $37^{\circ} \mathrm{C}$. A typical time course demonstrating the kinetics of growth and streptomycin production is shown in Fig. 2(a); in complex medium growth was rapid but streptomycin only began to appear as growth slowed, while in minimal medium growth was much slower but was accompanied by streptomycin formation. A plot of the highest streptomycin levels reached at each temperature is shown in Fig. 2(b). Whatever the medium, streptomycin production dropped to virtually zero at $34^{\circ} \mathrm{C}$, although at this temperature growth was still about $50 \%$ of that at $30{ }^{\circ} \mathrm{C}$. This strain of $S$. griseus thus clearly shows depression of streptomycin production at elevated growth temperatures in liquid media.

\section{Streptomycin production by S. griseus at standard and elevated growth temperature on solid media}

Streptomycetes in their natural environment, the soil, grow on the surfaces of particles; growth in liquid suspension is therefore in a sense unnatural. We therefore wished to examine whether the kinetics of streptomycin production, and its variation with growth temperature, differ as between cultures on solid and in liquid media. Cultures were grown (see Methods) on dialysis membranes placed on solid complex or minimal media. Growth was estimated by removing the membranes, washing, and estimating dry weight, while the streptomycin accumulated in the agar was determined by bioassay. The properties of the mycelia grown on solid media, such as heterogeneity due to diffusion limitation, partial anoxia, and degree of branching, might well be quite different as between solid-and liquid-grown cultures on media of the same composition. The kinetics of growth and strep- 

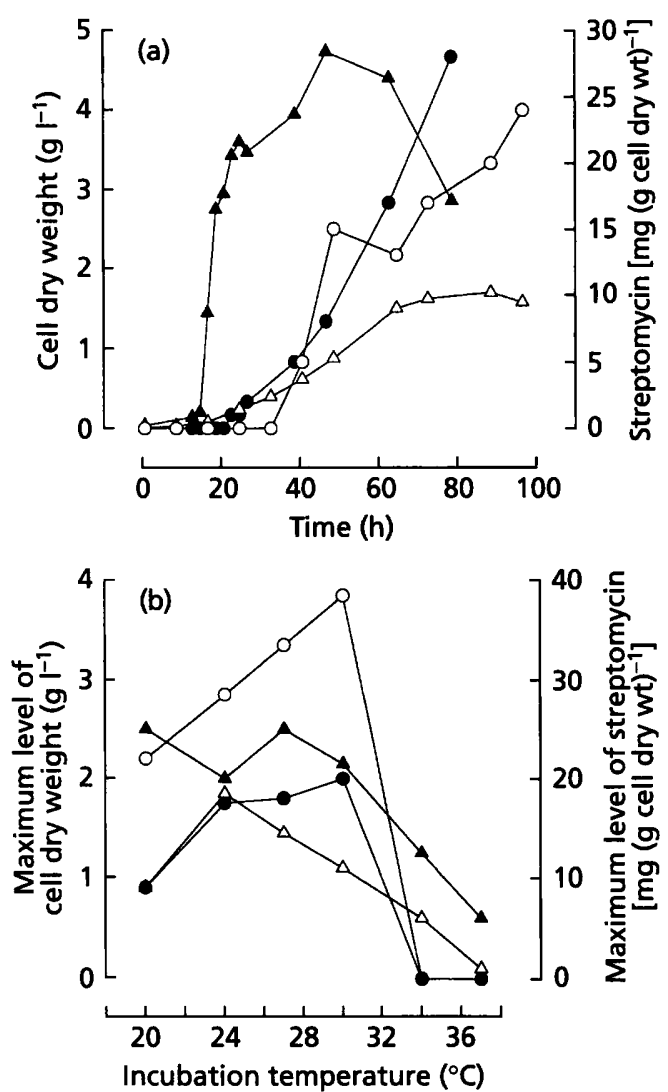

Fig. 2. (a) Growth and streptomycin yield in liquid cultures (see Methods) as a function of length of incubation at $30^{\circ} \mathrm{C} . \Delta, \Delta$, Cell dry weight in minimal medium $(\triangle)$ and complex medium (modified YEME) $(\Delta) ; O$, o, streptomycin yield in minimal medium (O) and complex medium (modified YEME) (O). (b) Growth and streptomycin yield in liquid cultures (see Methods) at different temperatures. The values plotted are the maximum values detected and are the means of duplicate experiments. Symbols as for (a).

tomycin yield on complex and minimal agar at $30^{\circ} \mathrm{C}$ as a function of time are shown in Fig. 3(a). On complex medium, streptomycin production lagged behind growth, whereas on minimal medium, they accompanied each other. These results are qualitatively very similar to those for liquid-grown cultures in the corresponding media shown in Fig. 2(a). Fig. 3(b) shows the variation of maximum streptomycin level with growth temperature on complex and minimal media. Though growth at $34^{\circ} \mathrm{C}$ was appreciable, streptomycin production was undetectable at this temperature. Again, behaviour on solid media is strikingly similar to that in the corresponding liquid media.

\section{Expression at $37^{\circ} \mathrm{C}$ of the aph reporter gene under the direction of PstrB1 in high copy number plasmid constructs}

A $200 \mathrm{bp}$ leader region separates PstrB1 from the beginning of $s t r B 1$. Because this shows a complex pattern of repeats and for other reasons, it was initially proposed
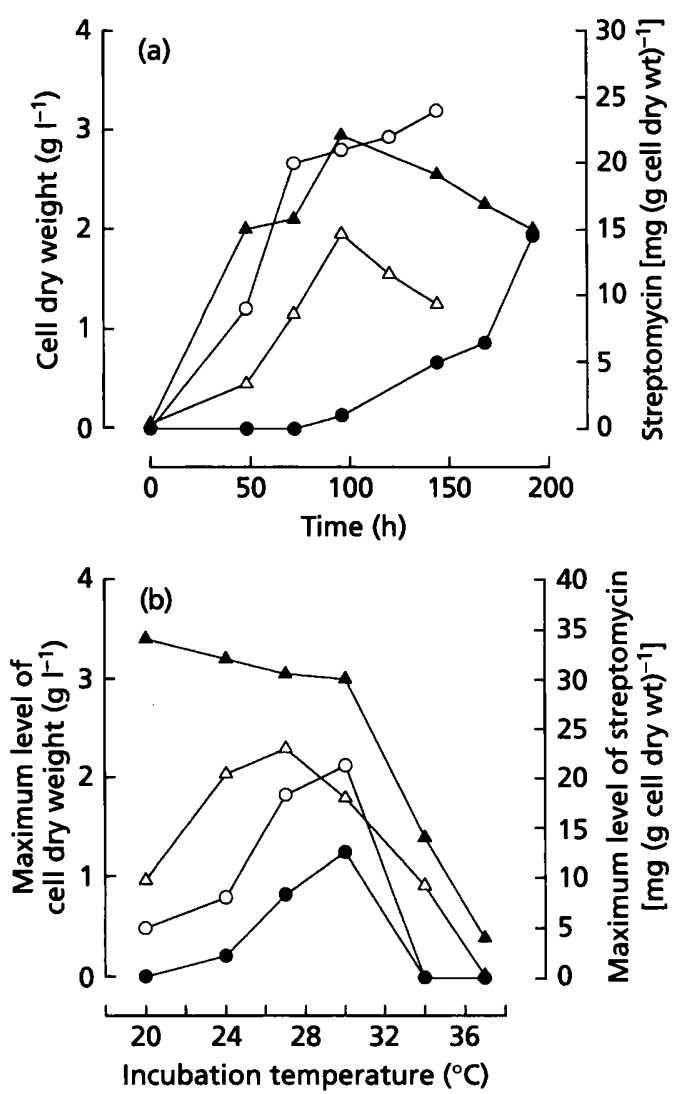

Fig. 3. (a) Growth and streptomycin level in the underlying agar medium as a function of length of incubation in cultures grown on solid media (see Methods) at $30^{\circ} \mathrm{C}$. Symbols as for Fig. 2(a). (b) Growth and streptomycin yield in cultures grown on solid media (see Methods) at different temperatures. Symbols as for Fig. 2(a).

that StrR might act as an anti-terminator to antagonize transcription termination within this region. This now seems unlikely, and StrR probably functions by binding to DNA in the vicinity of PstrB1 and stimulating the initiation of transcription there (Retzlaff et al., 1993). As shown in Fig. 1(a), two PstrB1-containing restriction fragments were used to construct fusions to reporter genes : a 'short' fragment which lacks most of the inverted repeats within the PstrB1-strB1 leader region, and a 'long' fragment which includes the entire leader region and the beginning of strB1. The DNA sequence of these fragments is given in Distler et al. (1987a, b). These fragments were cloned (Lindley et al., 1995) upstream of $a p h$ first in the pBR322-pIJ486 hybrid pHL623 to give plasmids pHL708 and 614 (Fig. 1 b), carrying the 'short' and 'long' fragments respectively. Two contiguous $P_{s t} \mathrm{I}$ fragments carrying the promoterless $a p h$ alone or $a p b$ fused to the 'short' or 'long' fragments were then cloned into pIJ702 to give pHL723, 728 and 714 respectively (Fig. 1 c). We showed (Lindley et al., 1995) that the 'short' fragment fused to $a p b$ in pHL708 and pHL728 directs StrR-independent APH expression. Results are shown in Table 2(a) for pHL723, 728 and 714 in S. lividans grown at 
Table 2. APH specific activities in S. lividans and S. griseus carrying aph gene fusions in high copy number

Cultures of $S$. lividans or $S$. griseus carrying the plasmids indicated were grown (see Methods) at the temperature shown, mycelium harvested, and its protein extracted and assayed for APH, as described in Methods. For the definitions of 'short' and 'long' promoter-bearing fragments, see Fig. 1. The number in parentheses following the mean is the number of determinations. Specific activities are in (units $\mathrm{mg}^{-1}$ ) $\times 10^{3}$.

\begin{tabular}{|c|c|c|c|c|}
\hline Plasmid & $\begin{array}{c}\text { Promoter- } \\
\text { bearing } \\
\text { fragment }\end{array}$ & $\begin{array}{c}\text { Mean APH } \\
\text { activity } \pm \text { SD } \\
\text { at } 30^{\circ} \mathrm{C} \dagger\end{array}$ & $\begin{array}{c}\text { Mean APH } \\
\text { activity } \pm \text { SD } \\
\text { at } 37^{\circ} \mathrm{C}\end{array}$ & $\begin{array}{l}\text { Ratio of mean } \\
\text { at } 30^{\circ} \mathrm{C} \text { to } \\
\text { mean at } 37^{\circ} \mathrm{C}\end{array}$ \\
\hline \multicolumn{5}{|c|}{ (a) Host: S. lividans } \\
\hline pHL723 & None & $4 \cdot 1(4) \pm 1 \cdot 0$ & $5 \cdot 0(3) \pm 1 \cdot 6$ & $0 \cdot 8$ \\
\hline pHL728 & 'Short' & $110(5) \pm 12$ & $37(4) \pm 6.9$ & $3 \cdot 0$ \\
\hline pHL714 & 'Long' & $8 \cdot 3(3) \pm 1 \cdot 9$ & $1 \cdot 3(3) \pm 0 \cdot 22$ & $6 \cdot 2$ \\
\hline \multicolumn{5}{|c|}{ (b) Host: S. griseus } \\
\hline pHL723 & None & $3 \cdot 5(4) \pm 1 \cdot 1$ & $4 \cdot 3(4) \pm 0 \cdot 71$ & $0 \cdot 8$ \\
\hline pHL728 & 'Short' & $110(6) \pm 6.5$ & $51(5) \pm 2 \cdot 7$ & $2 \cdot 2$ \\
\hline pHL714 & 'Long' & $47(7) \pm 3 \cdot 7$ & $6.9(6) \pm 1 \cdot 1$ & 6.8 \\
\hline
\end{tabular}

† Data from Lindley et al. (1995).

$30^{\circ} \mathrm{C}$ or $37^{\circ} \mathrm{C}$. APH activity in extracts of cultures carrying pHL723, lacking the PstrB1 promoter, was low and almost unchanged as between $30^{\circ} \mathrm{C}$ and $37^{\circ} \mathrm{C}$. Where the cultures carried pHL728, with the 'short' promoter fragment capable of directing aph expression in the absence of StrR, APH activity at $30^{\circ} \mathrm{C}$ was 27 -fold higher than with pHL723, and fell by a factor of about 3 at $37^{\circ} \mathrm{C}$. With pHL714, with the 'long' fragment unable to direct $a p h$ expression in the absence of StrR, APH activity at $30^{\circ} \mathrm{C}$ was not significantly different (by $t$-test) from that with pHL723. However, it fell at $37^{\circ} \mathrm{C}$ by an even larger factor, about 6 , than with pHL728; the activity at $37^{\circ} \mathrm{C}$ was not significantly different from that with pHL723 $(0.05<P<0.1$ by $t$-test $)$. As we did not possess a plasmid compatible with pHL708 that carried strR, the effect of growth at $37^{\circ} \mathrm{C}$ on StrR-activated expression of PstrB1 had to be carried out in $S$. griseus. Table 2(b) shows the APH activities in $S$. griseus at $30^{\circ} \mathrm{C}$ and $37^{\circ} \mathrm{C}$ directed by the same three plasmids. Activities with pHL723 were much as in S. lividans. Activity with pHL 728 at $30^{\circ} \mathrm{C}$ was identical to that in $S$. lividans, and at $37^{\circ} \mathrm{C}$ was not significantly different (again by $t$-test). With pHL714, at $30{ }^{\circ} \mathrm{C}$ the APH activity in S. griseus was only $42 \%$ of that with pHL728, implying that insufficient StrR was present for the high copy number plasmid. At $37^{\circ} \mathrm{C}$, APH activity was not significantly different from that with pHL723 $(0.05<P<0.1$ by $t$-test $)$.

Changes in copy number between $30^{\circ} \mathrm{C}$ and $37^{\circ} \mathrm{C}$ may affect the expression of cloned genes, especially for high copy number vectors. We have estimated pIJ702 copy number in $S$. griseus by subjecting mycelial total DNA extracts to agarose gel electrophoresis, the photographic trace after ethidium bromide staining then being scanned densitometrically (H. K. Lindley, unpublished results). The results suggest that at $37^{\circ} \mathrm{C}$ plasmid copy number is one-third to one-half that at $30^{\circ} \mathrm{C}$ (mean copy number approximately 100 and 250 respectively).

\section{Expression at $37^{\circ} \mathrm{C}$ of the $x y / E$ reporter gene under the direction of PstrB1 in low copy number plasmid constructs}

The availability of low copy number promoter-probe vectors such as pIJ2839 (Ingram et al., 1989; Clayton \& Bibb, 1990; Fig. 1d) based on SCP2*, and of $s t r R$ cloned in the pACYC184-pIJ702 hybrid pES2 (Fig. 1e; Lindley et al., 1995) permitted testing in S. lividans of the effect of growth at $37^{\circ} \mathrm{C}$ on PstrB1-directed expression of $x y l E$ in the presence of $s t r R$. The effect of the cloned $s t r R$ could be compared with that of the deletion variant $\operatorname{str} R \Delta 7$ (O'Neill, 1992; Lindley et al., 1995). Results for the nine possible combinations of promoter-bearing fragment (none, 'short' in pHL308, or 'long' in pHL314: Fig. 1D) and $s t r R$ allele cloned in pES2 (none, wild-type strR, or str $\mathrm{R} \Delta 7$ ) are shown in Table 3 . At $30^{\circ} \mathrm{C}$, as reported by Lindley et al. (1995), CO activities showed no increase with the 'short' fragment in the absence of StrR (pHL308/pES2) over those where no promoter-bearing fragment was present (pIJ2839 with any of the three pIJ702 derivatives). The presence of the cloned $s t r R$ in the companion plasmid gave an approximately 20 -fold increase in CO activity with both the 'short' and 'long' promoter-bearing fragments. $s t r R \Delta 7$ unexpectedly appeared to give appreciable stimulation of $x y l E$ expression with pHL308 - yielding a CO activity about $25 \%$ of that with strR - but not with pHL314 (the difference between mean activities with PHL314 and PIJ2839 is not significant by $t$-test). At $37^{\circ} \mathrm{C}$, no combination of promoter and $s t r R$ allele gave activity significantly above background, implying a lowering in $x y l E$ expression from that at $30^{\circ} \mathrm{C}$ by a factor of at least $\sim 30$. 
Table 3. CO specific activities in S. lividans carrying xylE gene fusions in low copy number

Cultures of $S$. lividans carrying the plasmids indicated were grown (see Methods) at the temperature shown, mycelium harvested, and its protein extracted and assayed for CO, as described in Methods. For the definitions of 'short' and 'long' promoter-bearing fragments, see Fig. 1. The number in parentheses following the mean is the number of determinations. Specific activities are in milliunits $\mathrm{mg}^{-1}$.

\begin{tabular}{|c|c|c|c|c|c|}
\hline $\begin{array}{l}\text { SCP2*-derived } \\
\text { plasmid } \\
\text { carrying } \\
x y I E(\text { Fig. 1d) }\end{array}$ & $\begin{array}{l}\text { Promoter- } \\
\text { bearing } \\
\text { fragment }\end{array}$ & 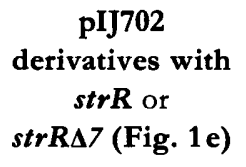 & $\begin{array}{c}\text { Mean } \mathrm{CO} \\
\text { activity } \pm \mathrm{SD} \\
\text { at } 30^{\circ} \mathrm{C} \dagger\end{array}$ & $\begin{array}{c}\text { Mean CO } \\
\text { activity } \pm \text { sD } \\
\text { at } 37^{\circ} \mathrm{C}\end{array}$ & $\begin{array}{l}\text { Ratio of mean at } \\
30^{\circ} \mathrm{C} \text { to mean at } \\
37^{\circ} \mathrm{C}\end{array}$ \\
\hline pI J2839 & None & pES2 & $4 \cdot 6(6) \pm 1 \cdot 1$ & $3.3(6) \pm 0.39$ & $1 \cdot 4$ \\
\hline pI J2839 & None & $\mathrm{pES} 2$ strR & $2 \cdot 4(5) \pm 0.49$ & $4 \cdot 3(6) \pm 1 \cdot 3$ & $0 \cdot 6$ \\
\hline pI J2839 & None & $\mathrm{pES} 2 \operatorname{str} \mathrm{R} \Delta 7$ & $4 \cdot 3(6) \pm 0.46$ & $4.0(6) \pm 0.90$ & $1 \cdot 1$ \\
\hline pHL308 & 'Short' & pES2 & $6 \cdot 7(6) \pm 1 \cdot 1$ & $4.7(6) \pm 0.66$ & $1 \cdot 4$ \\
\hline pHL308 & 'Short' & $\mathrm{pES} 2 s t r \mathrm{R}$ & $140(6) \pm 66$ & $4.7(6) \pm 0.77$ & 30 \\
\hline pHL308 & 'Short' & $\mathrm{pES} 2 s t r R \Delta 7$ & $36(6) \pm 7 \cdot 0$ & $4.9(6) \pm 0.65$ & $7 \cdot 3$ \\
\hline pHL314 & 'Long' & $\mathrm{pES} 2$ & $6.4(6) \pm 0.75$ & $6.1(6) \pm 0.95$ & $1 \cdot 1$ \\
\hline pHL314 & 'Long' & pES2strR & $190(6) \pm 75$ & $6.1(6) \pm 0.70$ & 32 \\
\hline pHL314 & 'Long' & $\mathrm{pES} 2 s t r R \Delta 7$ & $9 \cdot 2(6) \pm 2 \cdot 3$ & $6.5(6) \pm 0.82$ & $1 \cdot 4$ \\
\hline
\end{tabular}

† Data from Lindley et al. (1995), expressed in the units defined in this paper.

\section{DISCUSSION}

We have shown above that in S. griseus ATCC 12475, streptomycin production is depressed at elevated growth temperatures. This applies in both complex and minimal media, and both in liquid and on solid media.

Lindley et al. (1995) and others (Distler et al., 1987 b, 1992; Vujaklija et al., 1991) have shown that the 'short' Bam HI fragment, when fused to aph in high copy number $\mathrm{pIJ101-}$ based constructs, directs $\left(\right.$ at $\left.30^{\circ} \mathrm{C}\right)$ substantial levels of $\mathrm{APH}$ in S. lividans in the absence of StrR; on the other hand, as reported by Lindley et al. (1995), this fragment when fused to $x y l E$, whether in low copy number SCP2*based constructs or in high copy number pIJ101-based constructs, failed in the same situation to direct levels of $\mathrm{CO}$ above background with no promoter-bearing fragment present. The reason for this reporter gene dependent difference is unknown. The promoter activity of the 'short' fragment in S. lividans permitted the estimation of the effect of growth at $37^{\circ} \mathrm{C}$ on APH in the absence of StrR. aph expression directed by pHL728, carrying the 'short' PstrB1-bearing fragment fused to $a p b$ within pIJ702, fell threefold in S. lividans and twofold in S. griseus. It was pertinent to consider whether this reduction might be accounted for by a change in plasmid copy number. If the level of gene product were proportional to gene dosage - which is not always the case - the fall in StrRindependent APH activity directed by the 'short' fragment at $37^{\circ} \mathrm{C}$ in both $S$. lividans and $S$. griseus could be due solely to change in plasmid copy number. However, the activities directed by pHL714, with the 'long' fragment plus $a p h$ within $\mathrm{pIJ} 702$, determined solely in $S$. griseus due to the requirement for StrR activation, showed a considerably greater reduction, the activity at $37^{\circ} \mathrm{C}$ not being significantly different from the pHL723 control lacking a promoter fragment. This could be due to: (i) a greater drop in copy number for pHL714 than for pIJ702 and presumably for pHL728, which seems unlikely (because the replicon and most of the insert are the same in all cases) but cannot be ruled out; or (ii) a genuine reduction in StrR-activated PstrB1 expression. Trivial explanations based on enzyme instability for the reduction in APH specific activity in extracts from cultures grown at $37^{\circ} \mathrm{C}$ seem unlikely: as noted in Methods, no in vitro instability could be detected, while the similarity in activities conferred by the control plasmid pHL723 as between $30^{\circ} \mathrm{C}$ and $37^{\circ} \mathrm{C}$ in both S. lividans and S. griseus makes it unlikely that that the higher growth temperature causes the appearance of an APH-inactivating proteolytic activity.

With the SCP2*-based low copy number constructs with $x y l E$ as reporter gene, there is virtually no detectable increase in expression of the reporter gene at $37^{\circ} \mathrm{C}$ over the background without a promoter-bearing fragment. As the copy number of SCP2* is usually estimated as $1-2$ per chromosome (Hopwood et al., 1985), there seems to be little scope for attributing the difference at elevated growth temperature to change in copy number. Regarding explanations in terms of differential loss of enzyme activity at the higher temperature, there is again no indication of in vitro instability; and the appearance of a CO-inactivating proteolytic activity at the higher growth temperature is rendered improbable by the finding (V. J. Deeble, unpublished results) that when S. lividans TK54(pHL314)(pES2strR) is grown at $30^{\circ} \mathrm{C}$ and the temperature then shifted to $37^{\circ} \mathrm{C}$ for 1 or $2 \mathrm{~d}$, CO activity in extracts does not consistently diminish by comparison with that for a control whose incubation is continued at $30{ }^{\circ} \mathrm{C}$.

We suggest that the findings with $x y l E$ confirm the more likely explanation in the case of the high copy number constructs with aph, namely that the effectiveness of the StrR-activated PstrB1 promoter virtually disappears at 
$37^{\circ} \mathrm{C}$. StrR-independent expression of PstrB1 with the 'short' fragment construct pHL 728 seems to be less affected-possibly not at all-by growth at elevated temperature. The nature of this expression, shown by Lindley et al. (1995) to occur only when the reporter gene is $a p h$ and not when it is $x y l E$, is still unclear; but this result may indicate that elevated temperature has its effect through the StrR activation mechanism. Many reasons for this - not mutually exclusive - are possible. The StrR protein itself may be especially heat-labile, or its mode of action may be affected by the higher temperature. Also, $s t r R$ expression is thought to result from a regulatory cascade involving several other regulatory proteins acting at the DNA level; StrR level may therefore be affected by similar heat lability in one or more of these regulatory proteins or temperature sensitivity of their interaction with DNA. Further, at least the first of these regulatory steps involves a low molecular mass ligand, A-factor (Miyake et al., 1990; Vujaklija et al., 1993), and it may be that the availability of this compound is limited at elevated growth temperature. There is already an intriguing connection between A-factor and elevated temperature, in that growth of $S$. griseus at $37^{\circ} \mathrm{C}$ results in the accumulation of non-A-factor-producing variants (Hara \& Beppu, 1982). Finally, it has been suggested to us ( $T$. Kieser, personal communication) that the apparent temperature effect may be due to the lower solubility of oxygen at higher temperature; this possibility will be worth pursuing.

Granted that an effect of growth at elevated temperature is to reduce StrR-activated PstrB1 function - by whatever mechanism - to what extent does this explain the apparently complete loss of streptomycin production? It seems a priori likely that PstrB1 is not the only streptomycin biosynthesis promoter to show the effect. Reduced str gene expression could therefore be a major, or even the sole, cause of diminished streptomycin production even if the effect on PstrB1 and other promoters is less than $100 \%$, since: (a) there may be one enzyme in the streptomycin pathway whose activity is rate-determining, and expression of the gene for that enzyme may be especially sensitive to the temperature effect; or (b) even if all the str genes show only moderate effects, the sum total of these may be complete disappearance of flux through the pathway, a possibility predicted by metabolic control theory (Kell et al., 1989). In conclusion, we suggest that at least part of the reason for depression in streptomycin production at elevated growth temperatures is a failure in expression of genes encoding enzymes of streptomycin biosynthesis.

\section{ACKNOWLEDGEMENTS}

We thank Jenny Baker for preliminary work on the $x y / E$ system; Wolfgang Piepersberg and Jürgen Distler for helpful discussions and communication of results prior to publication; Mervyn Bibb, Tim Clayton, Jan Westpheling and Wolfgang Wohlleben for strains and advice; Tobias Kieser for useful comments on the manuscript; and E. J. Lucania of Squibb Research Labs, New Jersey, for the gift of thiostrepton. This work was supported by grants from the MRC, SERC, and
Wellcome Trust. H.K.L. and V.J.D. acknowledge SERC Research Studentships, and M.R.F. a studentship from the Iranian Government.

\section{REFERENCES}

Clayton, T. M. \& Bibb, M. J. (1990). Streptomyces promoter-probe plasmids that utilize the $x y l E$ gene of Pseudomonas putida. Nucleic Acids Res 18, 1077.

Distler, J., Braun, C., Ebert, A. \& Piepersberg, W. (1987 a). Gene cluster for streptomycin biosynthesis in Streptomyces griseus: analysis of a central region including the major resistance gene. Mol \& Gen Genet 208, 204-210.

Distler, J., Ebert, A., Mansouri, K., Pissowotzki, K., Stockmann, M. \& Piepersberg, W. (1987 b). Gene cluster for streptomycin biosynthesis in Streptomyces griseus: nucleotide sequence of three genes and analysis of transcriptional activity. Nucleic Acids Res 15, 8041-8056.

Distler, J., Mansouri, K., Mayer, G., Stockmann, M. \& Piepersberg, W. (1992). Streptomycin production and its regulation. Gene 115, 105-111.

Fazeli, M. R., Cove, J. H. \& Baumberg, S. (1995). Physiological factors affecting streptomycin production by Streptomyces griseus ATCC 12475 in batch and continuous culture. FEMS Microbiol Lett 126, 55-62.

Hara, O. \& Beppu, T. (1982). Mutants blocked in streptomycin production in Streptomyces griseus - the role of A-factor. $J$ Antibiot 35, 349-358.

Hopwood, D. A., Kieser, T., Wright, H. M. \& Bibb, M. J. (1983). Plasmids, recombination and chromosome mapping in Streptomyces lividans 66. J Gen Microbiol 129, 2257-2269.

Hopwood, D. A., Bibb, M. J., Chater, K. F., Kieser, T., Bruton, C. J., Kieser, H. M., Lydiate, D. J., Smith, C. P., Ward, J. M. \& Schrempf, H. (1985). Genetic Manipulation of Streptomyces: a Laboratory Manual. Norwich: John Innes Foundation.

Ingram, C., Brawner, M., Youngman, P. \& Westpheling, J. (1989). $x y l E$ functions as an efficient reporter gene in Streptomyces spp.: use for the study of galP1, a catabolite-controlled promoter. $J$ Bacteriol 171, 6617-6624.

Kell, D. B., van Dam, K. \& Westerhoff, H. V. (1989). Control analysis of microbial growth and productivity. Symp Soc Gen Microbiol 44, 61-93.

Lindley, H. K., Deeble, V. J., Peschke, U., O'Neill, M., Baumberg, S. \& Cove, J. H. (1995). Dependence on reporter gene of apparent activity in gene fusions of a Streptomyces griseus streptomycin biosynthesis promoter. Can J Microbiol 41, 407-417.

Martín, J.-F. \& Demain, A. L. (1980). Control of antibiotic biosynthesis. Microbiol Rev 44, 230-251.

Miyake, K., Kuzuyama, T., Horinouchi, S. \& Beppu, T. (1990). The A-factor-binding protein of Streptomyces griseus negatively controls streptomycin production and sporulation. $J$ Bacteriol 172, 30033008.

O'Neill, M. (1992). Genetic studies on the streptomycin biosynthesis system of Streptomyces griseus and its control. $\mathrm{PhD}$ thesis, University of Leeds.

Parker, R. E. (1973). Introductory Statistics for Biology. London: Edward Arnold.

Piepersberg, W. (1994). Streptomycin and related aminoglycoside antibiotics. In Biocbemistry and Genetics of Antibiotic Biosynthesis, pp. 71-104. Edited by L. Vining \& C. Stuttard. Stoneham, MA: Butterworth-Heinemann.

Retzlaff, L., Mayer, G., Beyer, S., Ahlert, J., Verseck, S., Distler, J. \& Piepersberg, W. (1993). Streptomycin production in strepto- 
mycetes: a progress report. In Industrial Microorganisms: Basic and Applied Molecular Genetics, pp. 183-194. Edited by R. H. Baltz, G. D. Hegeman, and P. L. Skatrud. Washington, DC: American Society for Microbiology.

Vallins, W. J. S. \& Baumberg, S. (1985). Cloning of a DNA fragment from Streptomyces griseus which directs streptomycin phosphotransferase activity. J Gen Microbiol 131, 1657-1669.

Votruba, J. \& Vanek, Z. (1989). Physicochemical factors affecting actinomycete growth and secondary metabolism. In Regulation of Secondary Metabolism in Actinomycetes, pp. 264-282. Edited by S. Shapiro. Boca Raton, FL: CRC Press.
Vujaklija, D., Ueda, K., Hong, S.-K., Beppu, T. \& Horinouchi, S. (1991). Identification of an A-factor-dependent promoter in the streptomycin biosynthetic gene cluster of Streptomyces griseus. Mol \& Gen Genet 229, 119-128.

Vujaklija, D., Horinouchi, S. \& Beppu, T. (1993). Detection of an Afactor-responsive protein that binds to the upstream activation sequence of $s t r R$, a regulatory gene for streptomycin biosynthesis in Streptomyces griseus. J Bacteriol 175, 2652-2661.

Received 3 July 1995; accepted 12 July 1995. 